\title{
Temporary Techno-social Gatherings? A (hacked) discussion about open practices
}

\author{
Luca M. Damiani \\ Tate \& London College of Communication \\ Tate \& University of the Arts London, UK \\ I.damiani@lcc.arts.ac.uk
}

\author{
Kat Braybrooke \\ University of Sussex Humanities Lab \\ Brighton, UK \\ k.braybrooke@sussex.ac.uk
}

\author{
John Philip Sage \\ John Philip Sage Design \\ London, UK \\ hello@johnphilipsage.com
}

\begin{abstract}
This paper is rooted in an experimental inquiry of issue-oriented temporary techno-social gatherings or TTGs, which are typically referred to as hackathons, workshops or pop-ups and employ rapid design and development practices to tackle technical challenges while engaging with social issues. Based on a collaboration between three digital practitioners (a producer, a researcher and a designer), qualitative and creative data was gathered across five different kinds of TTG events in London and in Tartu which were held in partnership with large institutions, including Art:Work at Tate Exchange within Tate Modern, the Mozilla Festival at Ravensbourne College and the 2017 Association of Internet Researchers conference hosted in Tartu. By analysing data using an open and discursive approach manifested in both text and visual formats, we reflect on the dynamic and generative characteristics of TTG gatherings while also arriving at our own conclusions as situated researchers and practitioners who are ourselves engaged in increasingly messy webs where new worlds of theory and practice are built.
\end{abstract}

Temporality. Art. Technology. Data. Collaboration. Embodiment. Participation. Remix. Hacks.

\section{INTRODUCTION}

Within the growing fields of creative technology and digital making, there is an ever-increasing materialization of temporary techno-social gatherings (TTGs) in the UK, typically referred to as hackathons, workshops or pop-ups, which bring together new art forms, new technologies and new methods for conceptual exploration (Damiani and Papadimitriou 2016; Briscoe and Mulligan 2014; Ratto 2011). Occurring over the span of a few hours or days, TTGs employ rapid design and development practices to tackle technical challenges while engaging with social issues. As a result of their collocation, or casual physical copresence (Trainer et al. 2016), they facilitate shared digital learning experiences while fostering new forms of networked connectivity. Like the $18^{\text {th }}$ century coffee houses of Habermas's Third Space, they have become an alternative public sphere for group experimentation, operating independently from other structural settings (Habermas 1991). Unlike $18^{\text {th }}$ century coffee houses, they explore new worlds both through the immateriality of software and the materiality of spaces for collaboration (DeVajuany \& Mitev 2013).
At their most transformative, temporary technosocial gatherings enable ground-breaking critical developments, fostering new models of grassroots innovation aligned to peer and open source production practices that challenge the way things are created, consumed and exchanged (Smith et al. 2016; Braybrooke 2016). However, in many cases TTGs also end up producing not only prototypes for new technologies, but also neoliberal subjects, reflecting a wider trend towards a specific kind of competitive, profit-driven technocracy originating from Silicon Valley (where the hackathon was also conceived) which valorises entrepreneurial citizenship (Cardullo et al. 2017; Lodato \& DiSalvo 2016; Irani 2015).

How can we, as digital practitioners and researchers whose work is materialised through increasingly entangled intra-relations of space, time and matter (Barad 2007), orient ourselves in a study of TTGs which are themselves manifested through increasingly complex webs of needs, desires and influences? How can we describe what it feels like to be embodied within these creative spaces, part of their temporarily inhabited performativity (Philips 1989) while working together with other actants, including technological objects (Law 2016; Martinez 2012) to build new worlds? 
How can we take note of the emergent nature of making, production and digital learning in TTGs when these practices arise from interactions that are, much like those of the networked economy, no longer temporally fixed (Hassan and Purser 2007)?

In this paper we have employed an experimental and discursive approach in our exploration of the ethereal nature of TGGs and their practices, enabling a different kind of flow from the typical academic piece to reflect the dynamic constitution of these gatherings. While we (Damiani and Braybrooke) co-developed the written aspects of the narrative, Sage responded through images instead of words, in doing so weaving design practice into the discussion of practice itself.

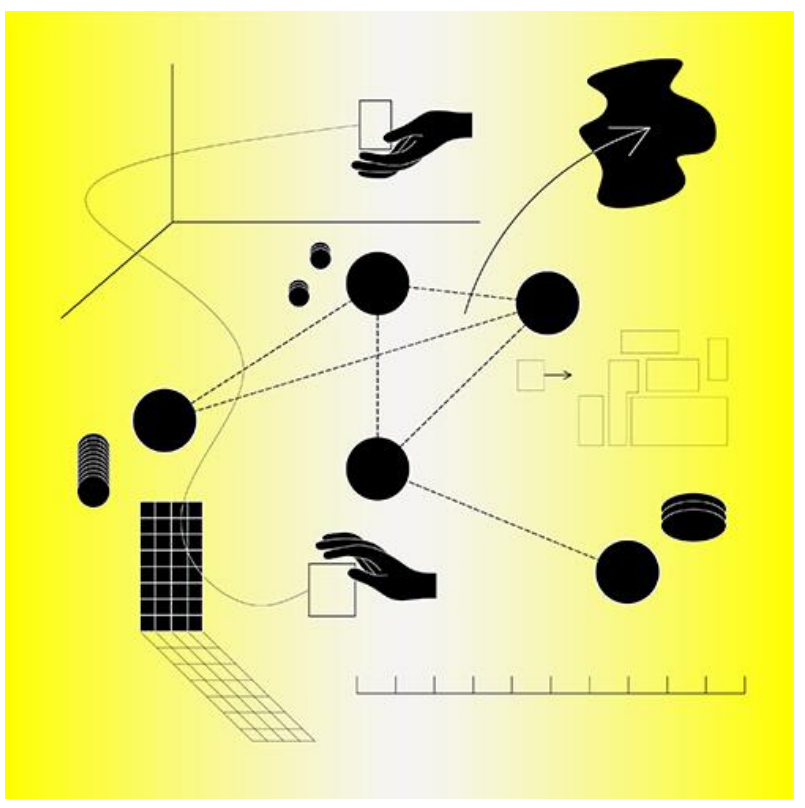

Figure 1: TTG definition diagram.

\section{SHARED MACHINES AND PRACTICES}

What does 'temporary' mean for a TTG - and how are shared machines and shared practices involved? How do interactions of space, time and matter define the interwoven prototypes built by actants in TTG environments? How are processes collectively shared amongst all? Like their less transient ancestors, shared machine shops (a term for hackerspaces, fablabs, makerspaces and other open workshops where people and tools gather together in a shared space), our research finds that TTGs are typically multidisciplinary and intensive in their interactions, bringing together human, machine and other organisms from a jumble of backgrounds that cut across art, design, computer science, digital culture, social science, government and the voluntary sector (Toombs et al. 2014).

Similar to the environment of a scientific laboratory, TTG practices (conceptualizing, prototyping, making, reiterating) are rooted in hands-on, collaborative experimentation, connecting shared machines and other digital tools with those who have the knowledge to work with them, and also with those who do not yet (Dickel et al. 2015). This making-as-learning approach to conceptual exploration allows TTGs to provoke discussions on technoscience-related topics that can be applicable to a wide variety of participants of all ages, especially younger generations (Friedewald \& Pohoryles 2014; Selwyn 2012; DeVries 2003). Issue-oriented temporary techno-social gatherings in particular have been found to uniquely address social concerns through experimental material participation (Lodato \& DiSalvo 2016). We were particularly interested in exploring how practices might manifest in institutional settings, such as museums, technology conferences and schools. This inquiry led to our creative participation in a series of TTG events in October of 2017.

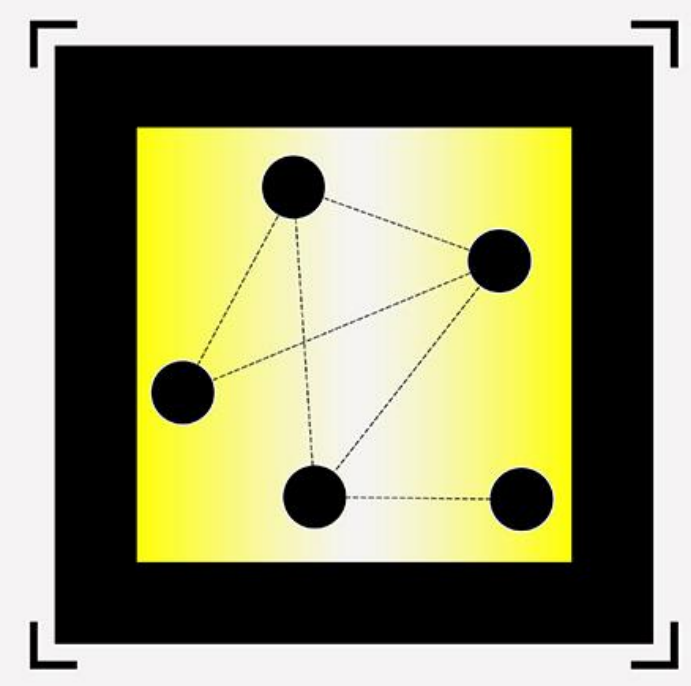

Figure 2: TTGs within institutional settings.

\section{METHOD}

In our aim to build an immersive, multi-sited (Marcus 1995) understanding of TTG practices across a variety of institutional environments, we engaged in asynchronous making and conceptbuilding at five different TTG-style events in London and Tartu throughout the month of October. Events included Tate Digital Learning's 'Art:Work' week at Tate Modern; the annual Association of Internet Researchers conference at the Dorpat Convention Centre in Tartu; the GlassRoom art intervention in an empty storefront in London; and finally the MisinfoCon at the Royal Society of the Arts and the Mozilla Festival also in London. We chose these events in particular because they were not only rooted in hands-on collaboration and the creation of 
prototypes like other TTGs, but were also issueoriented (Lodato \& DiSalvo 2016), aiming to critically address wider socio-technical concerns.

In order to collect observations on the practices of these events while also reflecting on the situated nature of our privilege as researchers and creative practitioners engaging with TTG environments (Haraway 1988), data was collected both through ethnographic field notes and through more creative inputs, which included sketches and diagrams. (Sanjek 1990; Emerson et al. 2011). By deploying both traditional qualitative methods such as ethnographic observation with more experimental making-as-learning approaches such as critical making (Ratto 2011), we took reference of our own lived embodiment as actants at these events (a term we draw from STS and actor-network theory to describe the agency of both human and nonhuman organisms in the traditions of Haraway, Law, Latour and many others). In this way, we were able to build a knowledge of the way we affected and were affected by - the complex webs of digital temporality and sociality built at TTG events.

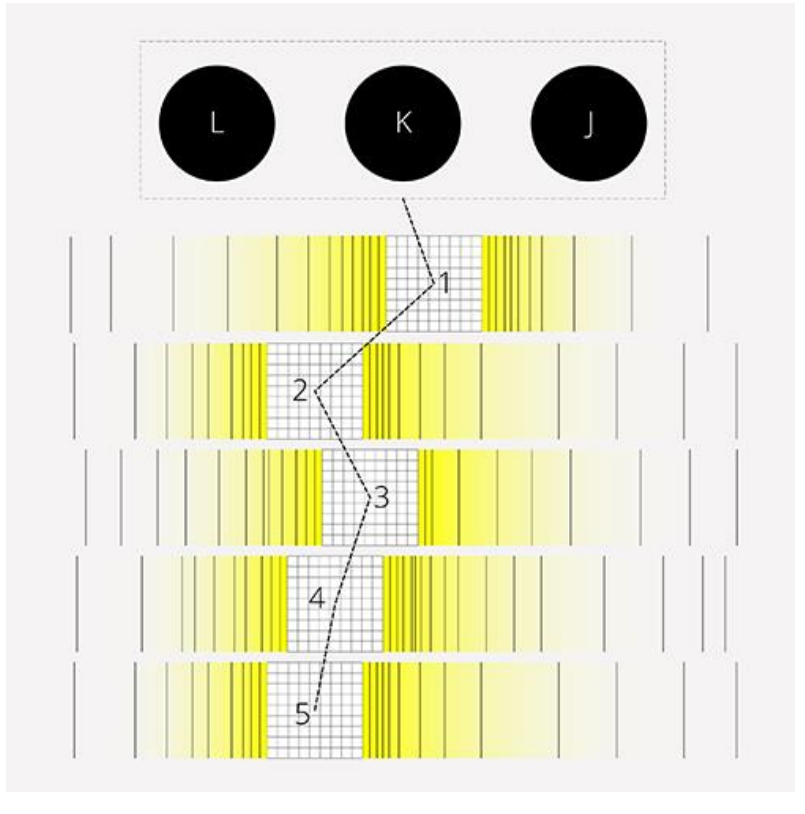

Figure 3: Engagement at five different TTG-style events.

\section{AN OPEN DISCUSSION : HACKED.}

To reflect on findings in an open format, we (Damiani as LD and Braybrooke as KB) have woven the data into a text-based conversation generated from our collocated observations at the five events we participated in; Sage (JS) has engaged with the discussion through visual interpretations that reflect both our exchanges and the on-site dynamics of the events themselves along with their flows. As an experiment in embodiment, participation and critique, this interaction is meant to be a starting point, allowing for further analysis, discussion and exploration.

LD: $13^{\text {th }}$ October, London. We are currently immersed in Art:Work, an art and technology TTG that is being performed within a temporary shared machine space on the publicly-engaged fifth floor of the new Tate Modern building, called Tate Exchange. Art:Work was conceived to explore the power and politics of production and making in an age of digital labour, and due to its setting within the gallery/museum, we felt its unique spatial circumstances (and those of other events like it) were worth examining further. I myself co-produced and co-curated Art:Work (together with Rebecca Sinker and Lou Macnamara) as part of our Tate Digital Learning programme. Kat and John were invited into the flow of making as collaborators, respectively as researcher and designer. Whilst working on our different creative developments onsite with an eye to active public engagement, we started having many unexpected conversations, which addressed a variety of topics in relation to data usage, privacy and conceptualising "work". Discussion has therefore become an important element of this event due to the high level of engagement amongst people of many different backgrounds who have joined us here.

KB: For me, the location of Art:Work and the fact that it was directed by artists and makers, not only the Tate, was significant. Like many large museums in London, the Tate remains a symbol of cultural hegemony for many, making it an unexpected setting for radically-minded gatherings of humans and machines like this one. And yet, it worked - thanks in large part to the receptiveness of Tate staff to artists' ideas, and to members of the public for jumping in and making with us - and the Exchange space saw many visitors come through its doors for Art:Work. I've been working in open technology for a while now, and I have never had more contacts from across that community convey how inspired they felt. This sends a powerful signal - one that says maybe it is possible for TTGs to foster structural change from within temporary autonomous sites that are hosted by larger branded spaces. However, there remain many issues around power to explore within such relationships, something we intend to investigate further through this collaboration piece and its intersections of time, space and the social.

JS: 


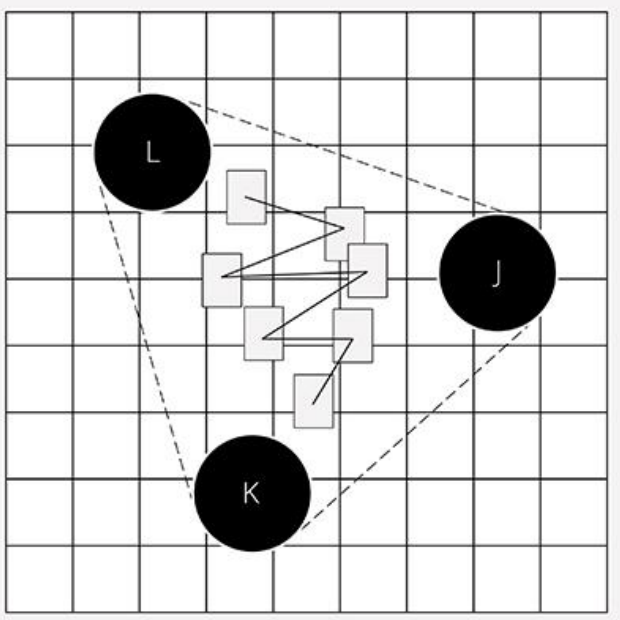

Figure 4: Luca, Kat and John at Art:Work.

LD: $14^{\text {th }}$ October, London. The Art:Work space is busy with people discovering the various resident artists' practices and analysing all the topics that have been introduced. Various discussions have come up that really struck me in terms of the diversity of perspectives regarding people's perceptions around metadata and privacy. Even while using apps daily and having many digital elements present in our lives, most of us still know very little of the actual textures of the digital worlds we live in. Some key questions were structured by participants to understand these interactions further.

- Is it difficult to know the digital in detail?

- What is privacy on the web, and is there a connection with its virtual/digital identity and its physicality?

- What is metadata?

- Do we know it as a concept; are we aware of its ingredients and potential?

- This knowledge is available as open access on the web, so why aren't we all aware of how our data is used and who it used by?

- What are the risks of being ignorant of this?

As they are asked, efforts are made to integrate questions like these directly into the participatory flow of Art:Work interventions like that of the artist Gary Stewart, who is performing a week-long interpretation of 'sneakerware', or data that is transmitted by foot. To illustrate this, he invites everyone to join him in chopping up and remixing various bits of conversation, audio, imagery and other outputs from across the space. As a result, there is a real sense of peer production in practice.
KB: l'd agree the spirit of peer production seems to be alive and well here. When the community who was brought together to envision this week, from Tactical Tech to Compiler, were given the Tate's brief to explore the politics of digital labour through making, we had many questions like these. How could we examine such a culturally-loaded set of topics through participatory methods that would engage users of all backgrounds and experience levels? How could tactical interventions be fostered to build a better understanding of the myriad platforms, interfaces, machines and systems that permeate our digital lives? There are no easy answers at an issue-oriented TTG, but it has been inspiring to see so many different kinds of people come by to make, hack and reflect on the issues with us. A few participants knew about Art:Work previously, but many of them were just walking through the Tate galleries and happened upon this floor by accident. The amazed looks on their faces as they realise they are encouraged to get their hands dirty by learning how to insert binary code into a vintage knitting machine, listening to what a shared machine shop in Japan sounds like, or building a customised cocktail out of their privacy settings, has been one of today's biggest surprises.

JS:

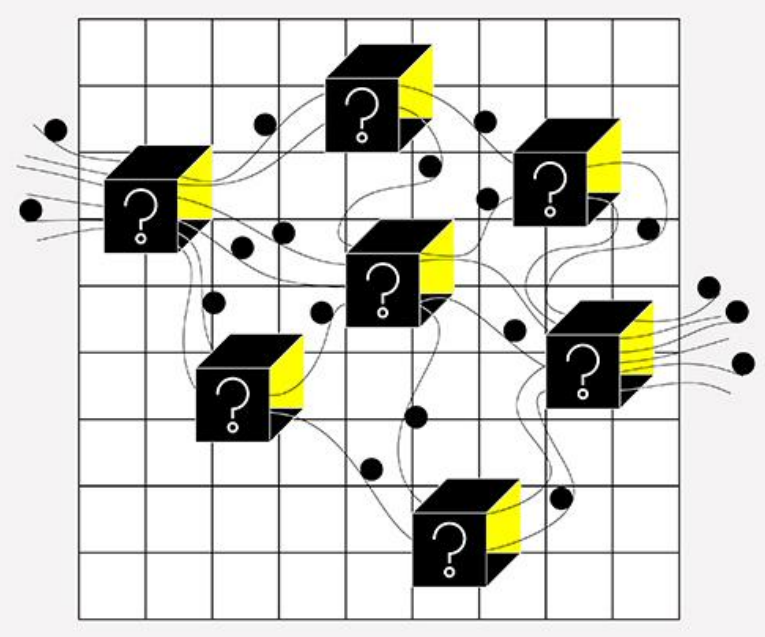

Figure 5: Visitors taking part in Art:Work.

LD: $15^{\text {th }}$ October, London. The many making-whilereflecting possibilities provided during Art:Work have inspired various groups - including myself! to engage further by thinking more deeply about data control and re-use. What are we doing with our data, they ask? Who is directing the remix? Are we in control of our digital data? And if we are, what happens when someone else is actually using or selling this data to third parties, in relation to their "free" online service (i.e. Facebook, Twitter, 
Instagram)? It is not only the concept of sharing data that mattered to people, but also what impact it had regarding privacy, ethics and the future (and present) aspects of digital labour. The concept of portraying and organising your life through social media, for example, actually starts to melt into free digital labour when you consider that every new message you share will be labelled, categorised, archived and sold into a bigger picture system of data collection. And so, this new idea of 'free' labour started flowing into the discussions that ended the week... yes, social media gives us a service, but for what price? As a participant explained:

It is our choice and responsibility to share online, but it is also important that the organisations owning all our data can make that more clear and transparent. For a certain degree, there is not enough knowledge around this. The majority of people [who came to the event] did not know about encryption (I've actually learned about it today) and did not know about all the different levels of automatisation and how our data can be used for political scopes, campaigns, fake news, etc. The terms and conditions are just crazy to read... who actually reads them?

KB: $19^{\text {th }}$ October, Tartu. I love the way the collocated messiness of TTGs can allow for serendipitous moments of peer learning like these. The 'freeness' of digital labour - both in a literal sense (we are supposedly free to produce what we want, and decide what we want to call 'labour') and in the materialist sense (meanwhile, we provide large companies with the fruits of our creative outputs, which they happily gather and profit from) is a discussion that many issue-based TTGs seem to be hosting right now, because these issues effect all web users with or without their consent. I am currently taking field notes at the annual AolR (Association of Internet Researchers) conference, an eclectic self-defined "internet researchers" that similarly aims to enable collaboration and peer-lead learning through immersive on-site collocation. I'm speaking on a panel that explores increasing fluidities of the so-called online/offline binary for digitally co-present (here I cite an excellent 2010 paper by Anne Beaulieu) subcultures like hackers, makers and gamers. For these communities (and indeed for the group of makers and thinkers who gathered around Art:Work), the digital permeates the physical so much that terms like "we lived most of our lives online" or "I'll see you offline" are no longer accurate. Instead, with the ubiquity of always-on mobile devices, tablets, computers, wearables and microchips, the 'real life' embodiment of our digital activities augments the life of even the most device-lite user. This really does muddy the waters when collaborating while situated together in a room ('actual' or 'virtual'); it is in moments like these that we really start to feel the effects of spatiality as a consensual experience of simultaneous time AND space, where the histories of a specific location (such as Tartu, and the global thinkers and makers who have gathered here) and its power-geometries are compressed by local and global influences that deeply affect our on-site interactions. Here, when managers of networked systems control the way they are used, data is subjugation - and the knowledge of how to subvert one's data traces becomes its own form of power.

JS:

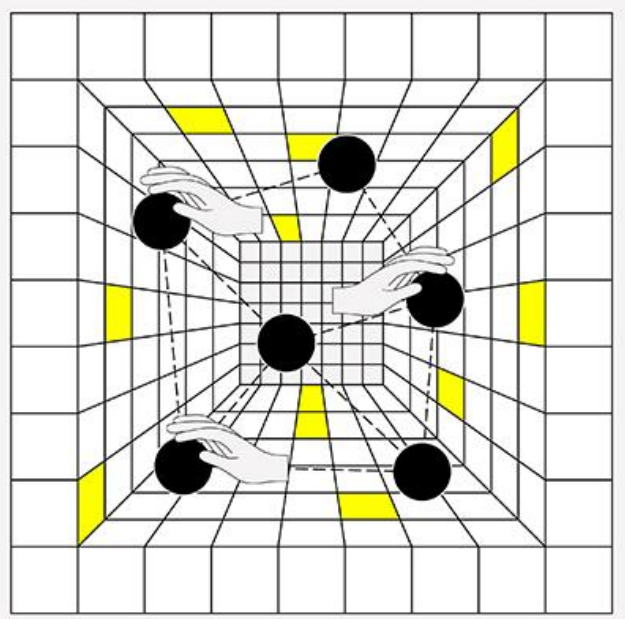

Figure 6: Materiality of spaces.

LD: $25^{\text {th }}$ October 2017, London, morning. I am now (together with a group of my Graphic and Media Design students from University of the Arts London) at The Glass Room, an art installation in the form of a 'pop-up tech store' aimed at creating a space for further reflection on how we live our lives online. The Tactical Technology Collective is running this in its entirety for the first time in the UK, after two short pop-up installations at both V\&A Digital Design Weekend in September 2017 and then Tate Exchange during the Art:Work shared machine shop ten days ago. Given we are connecting to other kinds of TTGs, this feels an especially interesting place to review a satirical one. In the space, everything is white. It has the feel of an Apple store or a brand new high-tech start-up. As you walk in, there are a variety of white plinths with a piece of technology on top of them, that at first look like Apple products but are actually art installations that 'educate' viewers around different topics of their online lives. The works mainly focus on privacy, with videos and interactive elements that explain the digital realities of data usage and how identities and activities are being used by third parties. I see this well-defined space as a direct contrast to the way our computational 
shared data is being used for nontransparent reasons, from marketing to consumer research to politics to data analysis for international military and policing. What do we really know about our data?

25th October 2017, afternoon. I am now at the Royal Society of the Arts in London, installing my video art piece about privacy as part of a pop-up exhibition for the MisinfoCon. MisinfoCon is a new conference that is part of Mozilla's cultural programme, and focuses on exploring digital misinformation, from fake news to terms and conditions. Its discussions have brought together a variety of perspectives from international policy to literacy, and the afternoon focuses on the global implications of misinformation, as well as trying to collaboratively identify methods for fighting it. From Mozilla:

\begin{abstract}
While it is not a new phenomenon, misinformation is compounded by both the speed that information travels in our networked world, and the technological and cultural "filter bubbles" that we live our lives in. This is a problem that impacts all of us. Our gathering seeks to strengthen the trustworthiness of information across the entire news ecosystem: journalism, platform, community, verification, fact checking and reader experience.
\end{abstract}

Connecting the co-location aspects of this conference to the Art:Work shared machine shop and the Glass Room tech pop-up, we see an increased value being placed on education around open practices and collaborative action.

KB: $27^{\text {th }}$ October, Manchester, the spiritual home of many of the UK's oldest industrialised machine shops, shared and otherwise (I suspect Marx would have something to say about this), and today the home of many inspiring community-led digital making projects, from the grassroots innovation organisation MadLab to the re-worked knitting machines of the artist Sam Meech, one of the featured makers in Art:Work with Tate. I'm interested to see what LD and JS think of the Mozilla Festival environment this weekend. Collaborating with a large, cause-based technology company like Mozilla can be a complicated experience. Its TTG events are well known in the tech community for bringing diverse participants together for issue-based activities (as we witnessed at the launch of the excellent Glass Room with Tactical Tech earlier this week, partly funded by Mozilla) that build new tools, principles, and projects aimed at enriching what the community calls a 'free and open web'. Mozilla is also a brand, its style guides and logo trademarks maintained by the Mozilla Corporation based out of San Francisco, its public interactions run by communications teams. When the Tate Digital Learning team invited us to collaborate on the
Art:Work project, it was clear that the interventions we planned as researchers and practitioners would be not restricted by Tate, and would instead be nurtured by the production team, who went out of their way to facilitate an open, egalitarian process for all involved. As a result, we felt free to build the outcomes together from a shared vision, and the happy buzz of activities that ensued during Art:Work coalesced into a temporary (yet lasting) community, which reflected that synchronicity. Building an environment based on open debate and shared respect is essential in the planning of issue-oriented TTGs that emerge in partnership with large institutions and companies - but it may not always be the case that the message survives the process of mediation in this way.

JS:

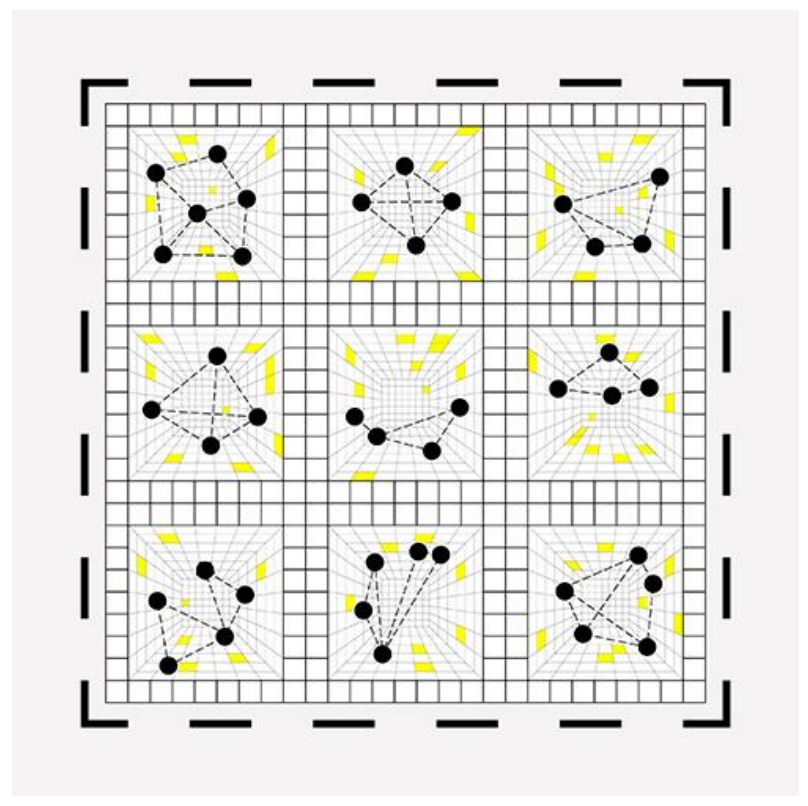

Figure 7: TTGs in large institutions.

LD: $28^{\text {th }}$ October 2017, London, noon. JPS and I are here at the first day of the Mozilla Festival. I agree with KB's previous reflection in part, as I also feel that branding was - and is - very 'present' at Tate, reflected in its methods of curating, dissemination, evaluation and audience shaping. Large public and community institutions like Mozilla and the Tate all start from their own brand, but ideally then the power goes to the people themselves and the grassroots philosophies they embody. Creating open and accessible works are very important for these kinds of institutions, because they need our outputs and ideas, which can mean an institutional reshaping of identities and letting go. At MozFest, led by the Mozilla Foundation and not Mozilla Corporation, the Artists Open Studios (co-curated by myself, Irini Papadimitrou from V\&A and Angela Plohman from Mozilla) are now flowing energetically after we took over the Ravensbourne College on Friday. That 
practical take-over of the building felt like a constructive and open act somehow...you get in on the Friday morning and you have around six hours to shape the building and host the entire festival. Mad. Good madness though, fully maintaining the open source community spirit. There are no media teams, or design teams, or marketing lenses... it is up to the participants, to the facilitators, to the community. Decentralised power and action. The Festival is, as always, full of energy and chaos...a chaos that is positive, open and allows exchanges and idea-forming of all kinds. With the Artist Open Studios, we wanted to create open laboratories where artists could be practicing live, and where the public would be an active participant in making. Through installations and real-time creations, the dynamic has been to collaborate by opening up new directions of debate about the web, with a focus on privacy and security, decentralisation, digital inclusion, open source and web literacy. More than four hundred facilitators are present at this year's festival, and artistic practices are intervening in the discussions, shaping new angles and perspectives.

Sunday 29th October 2017, evening: MozFest 2017 is finished... the building is emptied, cleaned, restructured to look like it did on Friday morning... feels like we have never been here. The materiality crossed over into the immateriality in exchanges of practices, discussions and thoughts... as per all the other TTG events we were part in these past few weeks (and the ones yet to come). Let's not forget these temporary shared machines...they are here, inside us; they are part of our beings now. We now know how to share more effectively than we did before, so let's make sure we go from temporary to longer-lasting in our debates.

$\mathrm{KB}$ : There really is something different about the temporality here. Having curated two tracks at previous iterations of Mozfest myself (Build and Teach the Web in 2013; Arts and Culture of the Web in 2014), I too felt that despite the Silicon Valley flavour that accompanies some of these TTGs, these remains a very strong grassroots, DIY and issue-oriented community energy amongst participants. In the case of Mozilla Festival's firstever Art and Culture track which I co-curated with Paula le Dieu, we were given the freedom to build an entire gallery from the ground up over the course of a few hours with our 12 featured artists, whose generative artworks explored various aspects of digital life by asking participants to get involved in helping build them - a lot like the combination of hands-on critical practice and concept-building that emerged during Art:Work at the Tate. There is something special that happens when makers and learners from different backgrounds are brought together around challenging ideas (and shared machines!) at a TTG that facilitates open and radical participation. Unexpected alliances are formed, minds are changed, projects are hatched, hegemonies are defied and status quos are shattered - for the most part. In the end, while we can never entirely separate such events from the structural circumstances and systems of power that helped birth them, we can attest to the many small yet powerful moments of liberation that are enabled when an institution provides publics with the space for strange and creative collocated experiments.

JS:

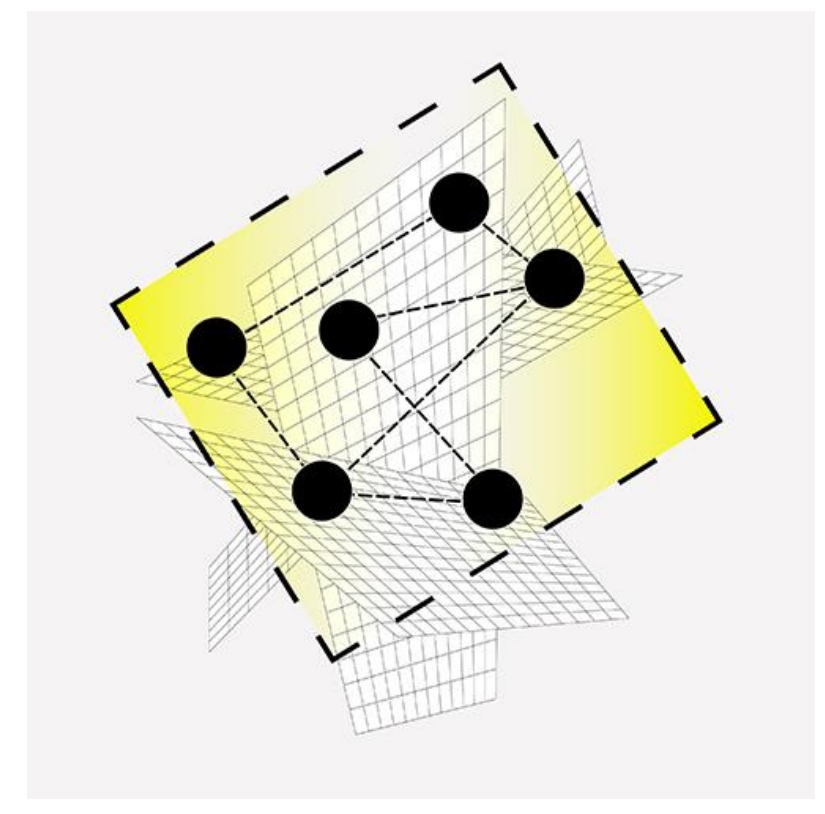

Figure 8: Moments of liberation within an institution.

\section{REFLECTIONS AND CONCLUSION}

Having shared in the previous paragraph some of our exchanges which occurred at the time of the TTGs observed, we then allowed ourselves to have a few months' detachment from the events in order to reflect on process of researching the temporal and rapid development of issue-oriented TTGs, while also engaging in collocated and asynchronous temporality ourselves as researchers and practitioners. Do TTGs have the power to make lasting changes, we wondered - or would it all be too temporary? While asking this question ourselves, we also decided to discuss it with many of the events' co-curators and co-producers.

Here, we share an especially thoughtful reflection from Rebecca Sinker (Digital Learning Convenor at Tate):

In referring to TTGs as not temporally grounded, we need to be careful not to neglect the evolving practices of which they are part... Art:Work, for example, grew out of a reflective practice that has been developed through time by the Digital 
Learning programme since 2011, and then developed with the opening of the Tate Digital Studio in late 2013 and the growth of a Digital Learning team through a collaborative practice, inspired in part by other artists-led digital spaces such as Backspace, Artec, The Redundant Technology Initiative and Furtherfield who were working collaboratively since at least the 90s. The interdisciplinary collaborative ecology created with the invitation to Art:Work artists and the subsequent development of the Art:Work TTG was very deliberately devised as part of an evolving digital learning practice, where previous work and experience directly influenced our decisions for co-devising this event. This practice holds collaboration as a core value and names 'an investigation into the affordances of digital technologies for learning through with and about art and artists' as a driving aim.

This response, together with other responses from co-producers of the other events we have considered in this piece, shows that while TTGs might feel "temporary" to us as collaborators, they are actually part of a much longer evolution of iteratively shared practices, discussions, strategies, planning sessions, and digital learning between individuals and institutions.

The intertwining of these "knotted analytical practices" between different actors echoes the kind of multi-species interactions Donna Haraway sought out in trying to develop a "cat's cradle" of discourse for critical engagement in technoscience studies (1994: 69). Much like a cat's cradle, the imprint of TTGs that has made the biggest impact has been that which continues to affect our research and creative practices as collaborators the mutually constitutive, chaotic, open and interwoven collective working flows which these events are situated around. By experimenting with open peer production methods for collaboration through the process of this research, for example, we have been implanted with an even stronger desire to implement such methods widely, and messily, wherever we can - whether that means toying with the process of academic knowledge production as we have done here, or rolling up our digital sleeves up to engage more directly in future gatherings which bring together actants of many agencies to co-create solutions to social concerns together. By engaging with 'worlding' in a Heideggarian sense, or the generative building of new world out of a multitude of possibilities through our self-interpretive actions even as we experience them, we have found that the critical and social aspects of concept-building that occurs at issueoriented TTGs makes a seemingly ethereal experience into something much less temporary.

The planting-of-seeds fostered by the human and machine organisms who interacted at the events we participated in - and our own situated actions and responses at those events - continue to build healthy trees of interaction amongst participants, branching out into moments of collaboration, inspiration and serendipity. While there are certainly some TTGs that end when the day itself ends, never to be formed again, in many cases the TTGs we observed evolved into coherent and lasting communities with their own cosmo-politics.

Furthermore, we have found that directly participating in the process of planning, producing and fostering an issue-oriented TTG can itself be a process of critical engagement. By openly sharing the fruits of group labour amongst many, the creation of new worlds is also enabled - worlds that challenge societal status quos in unexpected ways akin to the radical experiments of scientific laboratories (Dickel et al. 2014). The transformation of social structures and networks due to the emergence of TTGs and their unique temporalities is a phenomenon that we have only begun to grasp here. We look forward to the messy, strange and transformative cat's cradles yet to come.

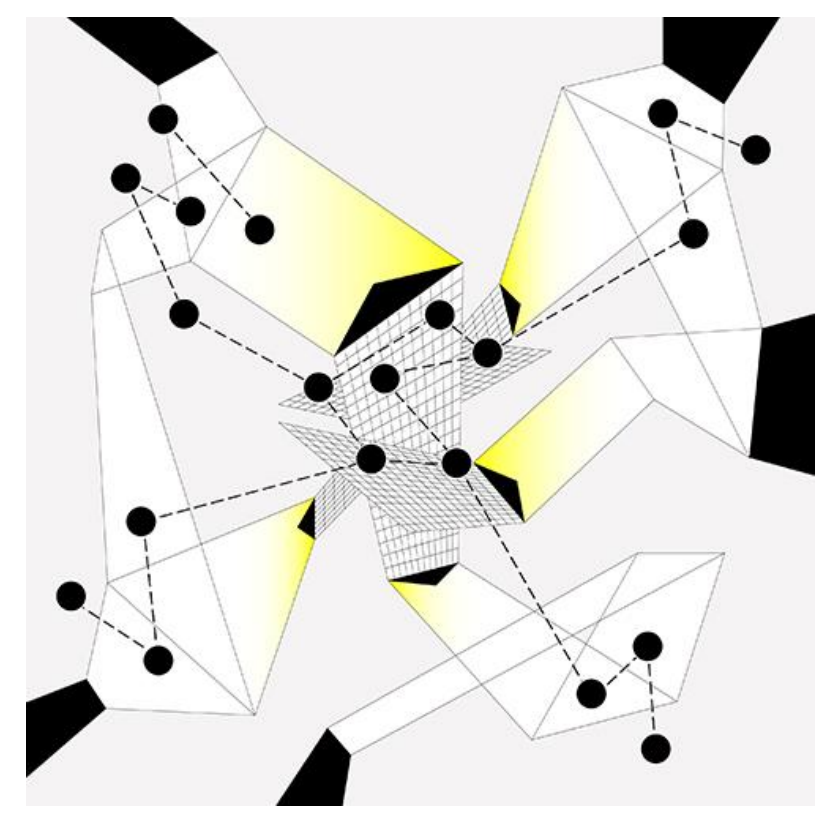

Figure 9: TTGs expanding beyond their temporality.

\section{REFERENCES}

Artists Open Studios, Mozilla Festival 2017. https://issuu.com/mozfest/docs/artistsopenstudios (retrieved 19 March 2018).

Art:Work. http://www.tate.org.uk/whats-on/tatemodern/tate-exchange/workshop/artwork (retrieved 19 March 2018).

Braybrooke, K. (2016) A Doctoral Day by Other Means: Power-geometries of space, community and $(\mathrm{R})$ evolution in El Poblenou. EASST Review, 35(4):51-54. 
Briscoe, G., and Mulligan, C. (2014) Digital Innovation: The hackathon phenomenon. Creative Works London.

Cardullo, P., Kitchin, R., and Di Feliciantonio, C. (2017) Living Labs and Vacancy in the Neoliberal City. Cities, 73:44-50.

Compiler Collective. http://compiler.zone (retrieved 19 March 2018).

Damiani L., and Papadimitriou, I. (2016) MozEx: Web? Arts? Tech? Experience? Electronic Visualisation and the Arts. British Computer Society.

DeVajuany, F., and Mitev, N. (2013) Materiality and Space - Organisations, Artefact and Practices. Palgrave MacMillan.

DeVries, W. (2003) Protecting Privacy in the Digital Age. Bereley Technology Law Journal, 18.

Dickel, S., Ferdinand, J., and Petschow, U. (2015) Shared Machine Shops as Real-Life Laboratories. Journal of Peer Production.

Emerson, R., Fretz, R., and Shaw, L. (2011) Writing Ethnographic Fieldnotes. University of Chicago Press.

Friedewald, M., and Pohoryles, R. (2014) Privacy and Security in the Digital Age. Routledge.

Gary Stewart Artist Portfolio.

http://www.garystewart.org (retrieved 19 March 2018).

Habermas, J. (1991) The Structural Transformation of the Public Sphere: An inquiry into a category of bourgeois society. MIT Press, Cambridge.

Haraway, D. (1988) Situated Knowledges: The science question in feminism and the privilege of partial perspective. Feminist Studies, 14(3):575599.

Hassan R., and Purser, R. (2007) 24/7: Time and Temporality in the Network Society. Stanford Business Books.

Heidegger, M. (1971) The Thing, trans. A. Hofstadter. Poetry, Language, Thought. Harper and Row, New York.
Irani, L. (2015) Hackathons and the Making of Entrepreneurial Citizenship. Science, Technology, \& Human Values, 40(5):799-824.

Law, J. (2016) STS as method. The Handbook of Science and Technology Studies. MIT Press, Cambridge, pp.31-55.

Lodato, T. J., and DiSalvo, C. (2016) Issue-oriented Hackathons as Material Participation. New Media \& Society, 18(4):539-557.

Marcus, G. (1995) Ethnography in/of the World System: The emergence of multi-sited ethnography. Annual Review of Anthropology, 24:95-117.

Martinez, M. (2012) Communication, Technology, Temporality in Futures of Communication Vol 1. https://scholarworks.umass.edu/cpo/vol1/iss $1 / 5$ (retrieved 19 March 2018).

MozFest. https://mozillafestival.org (retrieved 19 March 2018).

Phillips, P. C. (1989) Temporality and Public Art in Critical Issues in Public Art Vol. 48. College Art Association.

Ratto, M. (2011) Critical making: Conceptual and material studies in technology and social life. Information Society, 27(4):252-260.

Sam Meech. http://smeech.co.uk (retrieved 19 March 2018).

Sanjek, R. (1990) Fieldnotes: The Makings of Anthropology. Cornell University Press.

Selwyn, N. (2012) Making Sense of Young People, Education and Digital Technology: The role of sociological theory. Oxford Review of Education, 38.

Smith, A., Fressoli, M., Abrol, D., Arond, E., and Ely, A. (2016) Grassroots Innovation Movements. Routledge, New York.

Tactical Tech Collective. https://tacticaltech.org (retrieved 19 March 2018).

Toombs, A., Bardzell S., and Bardzell, J. (2014) Becoming Makers: Hackerspace member habits, values and identities. Journal of Peer Production, 5. 